\title{
PTSD and Depression After the Madrid March 11 Train Bombings
}

\author{
Juan J. Miguel-Tobal, Antonio Cano-Vindel, Hector Gonzalez-Ordi, and \\ Iciar Iruarrizaga \\ Complutense University of Madrid
}

Sasha Rudenstine and David Vlahov

New York Academy of Medicine

Sandro Galea

University of Michigan School of Public Health

\begin{abstract}
The March 11, 2004, train bombings in Madrid, Spain, caused the largest loss of life from a single terrorist attack in modern European history. We used a cross-sectional random digit dial survey of Madrid residents to assess the prevalence of posttraumatic stress disorder (PTSD) and major depression in the general population of Madrid 1 to 3 months after the March 11 train bombings. Of respondents 2.3\% reported symptoms consistent with PTSD related to the March 11 bombings and $8.0 \%$ of respondents reported symptoms consistent with major depression. The prevalence of PTSD was substantially lower, but the prevalence of depression was comparable to estimates reported after the September 11 attacks in Manhattan. The findings suggest that across cities, the magnitude of a terrorist attack may be the primary determinant of the prevalence of PTSD in the general population, but other factors may be responsible for determining the population prevalence of depression.
\end{abstract}

On the morning of March 11, 2004, 10 bombs left on four commuter trains in Madrid caused 191 deaths and injured more than 1,800 persons. It was the largest loss of life from a single terrorist attack ever in modern European history. In the days immediately after March 11, the attacks dominated national and international news, up to 2 million Madrilenos participated in protest demonstrations throughout the country, and a previously scheduled national election resulted in an upset election of the opposition party to power.
It has long been established that individual exposure to traumatic events (e.g., motor vehicle accidents, sexual assault) is associated with a substantial psychological burden (Foa, Davidson, \& Frances, 1999; Norris, Friedman, \& Watson, 2002b; Norris et al., 2002a), which probably starts in the immediate aftermath of the traumatic exposure and may persist in some persons for years after this exposure (North et al., 1999; Shalev, Tuval-Mashiach, \& Hadar, 2004). More recently it has also been shown that persons who are exposed to mass traumatic events (e.g., hurricanes,

We thank the Complutense University of Madrid (Grant SAP: 042AC00007), the Government of Madrid (Grant: 06/HSE/0266/2004), the Sociedad Española para el Estudio de la Ansiedad y el Estrés (SEAS) (Spanish Society of the Study of Anxiety and Stress), the Fundación Telefónica, and the National Institutes on Mental Health and the National Institutes on Drug Abuse for financial contributions to this research. We also thank the Colegio Oficial de Psicólogos (Spanish Psychological Association) for their supportive efforts.

Correspondence concerning this article should be addressed to: Sandro Galea, Department of Epidemiology, University of Michigan School of Public Health, Room 243 , 1214 S. University, Ann Arbor, MI 48104. E-mail: sgalea@umich.edu.

(C) 2006 International Society for Traumatic Stress Studies. Published online in Wiley InterScience (www.interscience.wiley.com) DOI: 10.1002/jts.20091 
industrial explosions) are also at risk for development of mental health problems after such events (Miguel-Tobal, González Ordi, \& Ortega, 2000). Studies that have assessed persons exposed to such disasters have documented mental health problems both among those who were immediate victims of these events (i.e., persons who were direct witnesses of the events), as well as among persons who were distant from the events but were indirectly affected by them (Schlenger et al., 2002). Existing studies also suggest that the psychological consequences of human-made disasters may be more profound in the general population than they are after natural disasters (Norris et al., 2002a, 2002b).

Terrorism represents an emerging threat of mass trauma that has the potential to affect large numbers of persons worldwide substantially. Research conducted in the aftermath of the Oklahoma City bombing of the Murrah Federal Building in 1995 showed that $34.3 \%$ of persons who were direct victims of the attacks suffered from posttraumatic stress disorder (PTSD) in the first 6 months after the attacks and $22.5 \%$ suffered from depression (North et al., 1999). A nationally representative study in Israel showed that $9.4 \%$ of the population had symptoms consistent with past-month PTSD (Bleich, Gelkopf, \& Solomon, 2003). These findings are consistent with those documented in two general population surveys of New York City conducted 1 to 2 months after September 11, 2001, which showed a prevalence of PTSD of 7.5\%-11.2\% among New York residents (Galea et al., 2002; Schlenger et al., 2002). PTSD linked to the September 11 terrorist attacks has also been documented in the general U.S. population, although the prevalence in the United States as a whole has been shown to be two to three times lower than it was in New York City in the first months after the September 11 attacks (Schlenger et al., 2002; Silver, Holman, McIntosh, Poulin, \& Gil-Rivas, 2002).

Our understanding of the general population consequences of mass traumatic events in general, and of terrorism in particular, however, remains limited. Therefore, in the aftermath of the March 11, 2004, train bombings in Madrid we conducted an assessment of PTSD and depression in the general population that was designed to be comparable to previous assessments in Manhattan and allow comparison across disaster contexts and across countries.

\section{METHOD}

\section{Data Collection and Sample}

Data were collected through telephone interviews with a random sample of Madrid city residents between April 13 and June 28, 2004, approximately 1 to 3 months after the March 11 attacks. The telephone sample was drawn from a published list of all household telephone numbers in Madrid; it is estimated that $92 \%$ of Madrilenos have a home phone and would therefore be eligible for this study (Instituto Nacional de Estadística, 2004). The Ethics Committee of the Faculty of Psychology of the Complutense University of Madrid approved the study, and oral informed consent was obtained.

The sampling frame consisted of adults living in households with telephones in Madrid. We oversampled residents of Madrid who lived within 1 kilometer of the three areas closest to the bombs' explosions. Upon random digit dialing, interviewers screened households for geographic eligibility, and an adult (at least 18 years old) in each household was randomly selected to be interviewed. Ten attempts to contact an adult at each number were made. Overall, 4,107 persons were contacted, and 1,589 interviews were completed, for an effective survey response rate of 38.7\% (American Association for Public Opinion Research, 2003).

Instruments. We adapted for this study a survey instrument that has previously been used to document the psychological consequences of the September 11, 2001, terrorist attacks in New York City (Galea et al., 2002). All questions were telephone administered and sequence of key domains was rotated randomly to minimize bias caused by the question sequence. The instrument was modified and adapted to reflect exposure to the March 11 train bombings and included the following question domains: demographics, experiences related to the attack, social 
support, perievent panic reactions, lifetime exposure to traumatic events, recent stressors, depression, and posttraumatic stress disorder. Psychometric properties of these question domains have been described elsewhere (Boscarino et al., 2004; Galea et al., 2003). The two key mental health domains of interest were PTSD and depression. We used the National Women's Study (NWS) PTSD module to assess PTSD symptoms since the March 11 bombings (Kilpatrick et al., 1998). The NWS PTSD module is a measure of PTSD that assesses the presence of criterion B (reexperiencing, e.g., intrusive memories, distressing dreams), C (avoidance, e.g., efforts to avoid thoughts associated with the trauma, loss of interest in significant activities), and D (arousal, e.g., difficulty falling asleep or concentrating) symptoms and determines content for content-specific symptoms (e.g., content of dreams or nightmares) if symptom presence is endorsed. Therefore, we were able to assess PTSD that was related to the March 11 bombings on the basis of the presence of at least one reexperiencing symptom specific to the attack, at least three avoidance symptoms (content specific where relevant), and two arousal symptoms. Persons who had one reexperiencing symptom, three avoidance symptoms, and two arousal symptoms but who did not link these symptoms to the March 11 terrorist attacks were considered to have PTSD not linked to the attacks.

Since its implementation, the NWS PTSD scale has been used in a number of large-scale mental health surveys involving over 16,000 completed telephone interviews (Galea et al., 2003; Hanson, Kilpatrick, Freedy, \& Saunders, 1995; Kilpatrick, Acierno, Resnick, Saunders, \& Best, 1997; Resnick, Kilpatrick, Dansky, Saunders, \& Best, 1993). The NWS PTSD module was externally validated in a field trial against the PTSD module of the Structured Clinical Interview for Diagnostic and Statistical Manual of Mental Disorders, third edition, revised (DSMIII-R) (SCID) administered by mental health professionals (Spitzer, Williams, Gibbon, \& First, 1992). In the field trial, instrument sensitivity was $99 \%$ and specificity was $79 \%$ when compared to SCID diagnosis (Kilpatrick et al., 1998). In addition, this PTSD scale had a reported kappa coefficient with the SCID of .71 for current PTSD
(Kilpatrick et al., 1998; Spitzer et al., 1992). In studies conducted after the September 11 terrorist attacks, alpha coefficient for the NWS PTSD module ranged from .86 to .90. The NWS PTSD module has also been compared to the PTSD Check List (PCL) (Blanchard, Jones-Alexander, Buckley, \& Forneris, 1996) among a random subsample of 229 participants in one of our surveys. That comparison found that the PCL had 75\% sensitivity and 95\% specificity in detecting PTSD cases as classified by our PTSD instrument (Boscarino et al., 2004). In a receiver operating characteristic analysis, against a PCL cutoff score equal to or greater than 50 (the optimal recommended cutoff), the PCL also optimally predicted PTSD using our instrument (area under the curve $=.97$ ) (Blanchard et al., 1996). Further details about the NWS PTSD module are available in other publications (Boscarino et al., 2004).

We assessed current (i.e., past 30 days) and lifetime symptoms of depression. For the presence of depression, we used an adapted version of the SCID's major depressive disorder (MDD) interview (Spitzer et al., 1992). The depression scale, which can also be scored continuously, had a Cronbach alpha of .79 in studies conducted after the September 11 terrorist attacks (Boscarino, Galea, Ahern, Resnick, \& Vlahov, 2003) and of .85 in the NWS (Kilpatrick et al., 2000). We have previously compared the results for depression in the past 30 days obtained by using our depression scale with those obtained by using the Brief Symptom Inventory 18 (BSI-18) depression scale (Derogatis, 2001). Overall, the BSI-18 depression scale had $73 \%$ sensitivity and $87 \%$ specificity in detecting depression as classified by our depression instrument (Boscarino et al., 2004). In receiver-operator characteristics analysis, the BSI depression cutoff score of greater than 65, which is the clinical cutoff for BSI depression, also optimally predicted depression when our instrument was used (area under the curve $=.89$ ) (Boscarino et al., 2004). We also assessed current (past 30 days) and lifetime depression symptoms. Further details about the depression measure used are available in other publications (Boscarino et al., 2004).

Administering the questionnaire took approximately 30 minutes. 
Table 1. Comparison of Survey Sample to Census Demographic Composition of Madrid

\begin{tabular}{|c|c|c|c|}
\hline & $\begin{array}{l}\text { Population ( } \geq 18 \text { years old) percentage from } \\
2001 \text { Madrid Census }(N=2,494,709)\end{array}$ & $\begin{array}{l}\text { Sample }(\geq 18 \text { years old }) \\
\text { weighted percentage }(N=1,589)\end{array}$ & Chi square \\
\hline Gender & & & 0.001 \\
\hline Male & 45.9 & 47.1 & \\
\hline Female & 54.1 & 52.1 & \\
\hline Age & & & 0.036 \\
\hline $18-29$ & 21.7 & 26.3 & \\
\hline $30-44$ & 28.7 & 22.5 & \\
\hline $45-59$ & 20.8 & 25.5 & \\
\hline$\geq 60$ & 28.8 & 25.6 & \\
\hline Residence by district & & & 0.763 \\
\hline 1 & 4.5 & 4.0 & \\
\hline 2 & 4.5 & 4.4 & \\
\hline 3 & 4.2 & 3.5 & \\
\hline 4 & 4.9 & 4.4 & \\
\hline 5 & 4.5 & 4.9 & \\
\hline 6 & 4.8 & 4.8 & \\
\hline 7 & 5.0 & 5.4 & \\
\hline 8 & 6.8 & 6.8 & \\
\hline 9 & 3.7 & 3.6 & \\
\hline 10 & 8.7 & 8.3 & \\
\hline 11 & 7.5 & 6.2 & \\
\hline 12 & 4.0 & 3.9 & \\
\hline 13 & 7.4 & 7.6 & \\
\hline 14 & 3.6 & 4.2 & \\
\hline 15 & 7.5 & 7.0 & \\
\hline 16 & 4.8 & 6.0 & \\
\hline 17 & 4.2 & 4.0 & \\
\hline 18 & 1.9 & 1.9 & \\
\hline 19 & 1.7 & 2.8 & \\
\hline 20 & 4.6 & 5.1 & \\
\hline 21 & 1.2 & 1.3 & \\
\hline
\end{tabular}

Statistical analysis. Sampling weights were developed and applied to the data to correct for potential selection bias related to the number of household telephones, persons in the household, and oversampling. We report prevalence of lifetime, current (within the past 30 days), March 11specific, and current non-March 11-specific PTSD and the prevalence of lifetime and current depression. We used 2-tailed chi-square tests to assess the bivariate relations between prevalence of current March 11-related PTSD and of current (within the past 30 days) depression with each of the covariates of interest. Multiple logistic regression was used to examine predictors separately for current PTSD and depression. Differences in log-likelihood were used to determine whether variables were retained in subsequent models. Independent variables were retained in the final model if they were statistically significant at $p \leq .05$.

\section{Results}

Sample. We surveyed 1,589 persons overall. Mean age of the sample was 45.5 years $(S E=0.64), 52.1 \%$ were women (age range 18 to 92 years; mean age $=46.7, S E=0.79$ ), and $47.1 \%$ were males (age range 18 to 96 years; mean age $=44.2, S E=1.02)$. Table 1 shows age, sex, and residence distributions in our sample compared to the Madrid 
Table 2. Comparison of Prevalences of Posttraumatic Stress Disorder and Depression Between March 11, 2004, in Madrid and September 11, 2001, in Manhattan, NY City

\begin{tabular}{|c|c|c|}
\hline & $\begin{array}{c}\text { Madrid prevalence } \\
\%(95 \% \text { confidence interval })\end{array}$ & $\begin{array}{l}\text { New York City prevalence } \\
\% \text { (95\% confidence interval) }\end{array}$ \\
\hline \multicolumn{3}{|l|}{ Posttraumatic } \\
\hline Ever & $12.2 \%(10.3-14.5)$ & $19.3 \%(16.6-22.0)$ \\
\hline Since events & $4.0 \% \quad(2.9-5.5)$ & $8.9 \% \quad(7.0-10.8)$ \\
\hline Terrorist attacks-related & $2.3 \% \quad(1.6-3.4)$ & $7.5 \% \quad(5.7-9.3)$ \\
\hline \multicolumn{3}{|l|}{ Depression } \\
\hline Ever & $26.8 \%(24.1-29.6)$ & $27.0 \%(23.9-30.1)$ \\
\hline Since events & $8.0 \% \quad(6.3-10.1)$ & $9.7 \% \quad(7.6-11.8)$ \\
\hline \multicolumn{3}{|l|}{ PTSD and depression } \\
\hline Since events & $2.0 \% \quad(1.2-3.2)$ & $4.4 \% \quad(3.0-5.8)$ \\
\hline Terrorist attacks-related & $1.4 \% \quad(0.8-2.3)$ & $3.7 \% \quad(2.4-5.0)$ \\
\hline \multicolumn{3}{|l|}{ PTSD or depression } \\
\hline Since events & $9.5 \% \quad(7.7-11.6)$ & $14.3 \%(11.9-16.7)$ \\
\hline Terrorist attacks-related & $8.4 \% \quad(6.7-10.5)$ & 13.6\% (11.2-16.0) \\
\hline
\end{tabular}

Note. PTSD $=$ Posttraumatic stress disorder.

2001 Census. There were no statistical differences between our sample and the Madrid 2001 Census.

\section{Prevalence of PTSD and Depression}

The prevalence of current PTSD related to the March 11 terrorist attacks in our sample was $2.3 \%$ (95\% confidence interval $=1.6 \%-3.4 \%)($ Table 2$)$. We also assessed prevalence of current PTSD that was not related to the March 11 attacks. Of those sampled $1.7 \%$ had symptoms consistent with current PTSD not related to the March 11 attacks. Among residents in the areas of oversample, i.e., the areas closer to the train bombings, the prevalence of PTSD was 4.3\% (95\% CI $=2.2-8.3$ ). Lifetime prevalence of PTSD in the overall sample was $12.2 \%(95 \% C I=10.3-14.5)$. The prevalence of current depression was $8.0 \%(95 \%$ $C I=6.3 \%-10.1 \%$ ), and among residents in the areas of oversample the prevalence of depression was $10.4 \%$ (95\% $C I=6.9-15.3)$. Lifetime prevalence of depression was $26.8 \%$. Overall, $8.4 \%$ (95\% CI $=6.7-10.5)$ of the respondents reported either PTSD or depression and $1.4 \%$ (95\% CI $=0.8-2.3)$ reported symptoms that met criteria for both disorders in our sample (Table 2).

\section{Bivariate Analusis}

Table 3 shows the results of bivariate analyses. The covariates associated with PTSD were sex $(p=.001)$, age $(p<.05)$, level of social support $(p=.001)$, number of life stressors in the 12 months before March 11 ( $p=.001$ ), and whether the respondent had a panic attack during or soon after the events $(p=.001)$ or directly witnessed the events $(p<.01)$.

Covariates associated with depression were sex $(p<$ $.001)$, level of social support $(p=.008)$, number of life stressors in the 12 months before March $11(p<.001)$, whether the respondent had a panic attack during or soon after the events $(p<.001)$ or directly witnessed the events $(p<.05)$, and fear of personal injury or death $(p<.01)$.

\section{Multivariate Analusis}

In a multivariate logistic regression model (Table 4), significant predictors of PTSD were sex, women as compared with men (odds ratio, 2.6); age, 18 to 29 years old (odds ratio, 9.8), 30 to 44 years old (odds ratio, 9.1), 45 to 59 years old (odds ratio, 7.6), as compared with 60 years old or older; low as compared with high level of social support 
Table 3. Bivariate Associations Between Characteristics of the Respondents and Current Posttraumatic Stress Disorder or Depression

\begin{tabular}{|c|c|c|c|c|c|}
\hline Variable & Number of respondents & PTSD (\%) & $p$ value & Depression (\%) & $p$ value \\
\hline Total & 1,589 & 2.3 & & 8.0 & \\
\hline Sex & & & $* *$ & & $.001^{* *}$ \\
\hline Male & 717 & 0.9 & & 5.1 & \\
\hline Female & 855 & 3.6 & & 10.6 & \\
\hline Age & & & $*$ & & ns \\
\hline $18-29$ & 342 & 4.1 & & 11.7 & \\
\hline $30-44$ & 437 & 2.7 & & 6.1 & \\
\hline $45-59$ & 365 & 2.3 & & 7.1 & \\
\hline$>60$ & 427 & 0.2 & & 7.1 & \\
\hline Social support & & & ** & & $.008^{* *}$ \\
\hline High & 526 & 1.7 & & 4.9 & \\
\hline Medium & 703 & 1.6 & & 8.5 & \\
\hline Low & 343 & 5.2 & & 12.6 & \\
\hline $\begin{array}{l}\text { Number of life stressors } 12 \\
\text { months before March 11, } 2004\end{array}$ & & & ** & & $.001^{* *}$ \\
\hline 0 & 726 & 0.7 & & 3.9 & \\
\hline $1-2$ & 702 & 2.1 & & 7.3 & \\
\hline 3 or more & 157 & 10.4 & & 29.0 & \\
\hline $\begin{array}{l}\text { Symptoms of panic attack } \\
\text { during or soon after the events }\end{array}$ & & & $* *$ & & $* *$ \\
\hline No & 1,403 & 0.9 & & 6.2 & \\
\hline Yes & 186 & 13.5 & & 23.8 & \\
\hline Directly witnessed the events & & & $* *$ & & $*$ \\
\hline No & 1333 & 2.0 & & 7.5 & \\
\hline Yes, in person & 164 & 8.3 & & 17.2 & \\
\hline $\begin{array}{l}\text { Were on a train during the } \\
\text { bombings }\end{array}$ & & & ns & & ns \\
\hline No & 1,532 & 0.0 & & 7.8 & \\
\hline Yes & 17 & 2.4 & & 17.5 & \\
\hline Friend or relative killed & & & ns & & ns \\
\hline No & 1541 & 2.2 & & 7.9 & \\
\hline Yes & 48 & 6.1 & & 10.5 & \\
\hline Fear of personal injury or death & & & ns & & $* *$ \\
\hline No & 972 & 1.9 & & 5.8 & \\
\hline Yes & 567 & 2.4 & & 11.8 & \\
\hline Involved in rescue effort & & & ns & & ns \\
\hline No & 1,501 & 2.3 & & 8.1 & \\
\hline Yes & 66 & 3.6 & & 6.8 & \\
\hline Annual household income & & & ns & & ns \\
\hline$<12,00 €$ & 239 & 2.8 & & 13.7 & \\
\hline $12,001 €-24,000 €$ & 305 & 2.8 & & 7.7 & \\
\hline $24,001 €-36,000 €$ & 175 & 1.7 & & 6.7 & \\
\hline$>36,001 €$ & 148 & 2.2 & & 7.0 & \\
\hline
\end{tabular}


Table 3. Continued

\begin{tabular}{lccccc}
\hline Variable & Number of respondents & PTSD (\%) & $p$ value & Depression (\%) & $p$ value \\
\hline Education & & & $n s$ & & $n s$ \\
No education & 44 & 0.0 & & 14.6 & \\
6-12 years (elementary) & 250 & 2.8 & & 9.5 & \\
13-16 (junior high school) & 179 & 3.2 & & 7.5 & \\
17-18 (senior high school) & 487 & 2.0 & & 7.7 & \\
19-21 (1st cycle university) & 187 & 2.7 & & 5.0 & \\
21-23 (2nd cycle university) & 323 & 1.5 & & 4.0 & $n s$ \\
$>23$ (master's, doctorate) & 58 & 2.0 & $n s$ & 7.9 & \\
Lived close to the bombings & & & & 10.4 & \\
No & 1,265 & 2.3 & & & \\
Yes & 324 & 4.3 & & &
\end{tabular}

(odds ratio, 2.1), one or two (odds ratio, 2.4); and three or more (odds ratio, 7.4) life stressors in the 12 months before March 11 as compared with none; presence of symptoms consistent with a panic attack during or soon after the events as compared with none (odds ratio, 8.2); and direct witnessing of the event (odds ratio, 2.9). The significant predictors of depression were female sex (odds ratio, 1.7); one or two (odds ratio, 1.9) and three or more life stressors (odds ratio, 7.1), as compared with none; symptoms consistent with a panic attack during or soon after the events as compared with none (odds ratio, 3.4); having direct witnessing of the event (odds ratio, 1.7); and fear of personal injury or death during or soon after the events (odds ratio, 2.1).

\section{Discussion}

This study used comparable methodology and instruments to those previously employed in Manhattan in the first 1 to 2 months after the September 11, 2001, terrorist attacks (Galea et al., 2002). As such, it provides us with a unique opportunity to compare the prevalence of PTSD and depression in two different populations after different terrorist attacks while minimizing possible differences caused by the study design.

Our survey of the general population of Madrid after the March 11 Madrid train bombings found that only $2.3 \%$ of respondents had symptoms consistent with current PTSD related to the March 11 bombings, and another $1.7 \%$ of persons had symptoms consistent with PTSD that were not linked to the bombings. After the September 11, 2001, terrorist attacks in Manhattan the prevalence of current PTSD related to the September 11 attacks was substantially higher at $7.5 \%$, although the proportion of persons who had symptoms consistent with current PTSD not related to the terrorist attacks (1.4\%) was very similar to the proportion obtained in the Madrid sample. In this study, among residents living in the areas close to the train bombings, the prevalence of PTSD was 4.3\%; the comparable prevalence in the area close to the World Trade Center (WTC) after the September 11 terrorist attacks was 20\%.

We found that $8.0 \%$ of respondents had symptoms consistent with current depression, which was comparable to the $9.7 \%$ estimate of current depression among residents of Manhattan after the September 11, 2001, terrorist attacks. In this survey, among those living close to the bombings, the prevalence of depression was $10.4 \%$, which was comparable to $16.8 \%$ in the area close to the WTC after the September 11 attacks. Lifetime prevalence of PTSD in our sample was $12.2 \%$, compared to $19.3 \%$ in the Manhattan sample after September 11, 2001, suggesting that the primary difference in this lifetime PTSD estimate was the current terrorist-attack-related prevalence of PTSD in the Manhattan sample. Lifetime prevalence of depression was comparable in the Madrid (26.8\%) and Manhattan (27.0\%) samples. 
Table 4. Multivariate Associations Between Characteristics of the Respondents and Current Posttraumatic Stress Disorder or Depression

\begin{tabular}{|c|c|c|c|c|}
\hline & \multicolumn{2}{|r|}{ PTSD } & \multicolumn{2}{|r|}{ Depression } \\
\hline & Odds ratio & 95\% Confidence interval & Odds ratio & $95 \%$ Confidence interval \\
\hline \multicolumn{5}{|l|}{ Sex } \\
\hline Male & 1.0 & & 1.0 & \\
\hline Female & 2.6 & $(1.4-4.9)$ & 1.7 & $(1.1-2.7)$ \\
\hline \multicolumn{5}{|l|}{ Age } \\
\hline$\geq 60$ & 1.0 & & & \\
\hline $45-59$ & 7.6 & $(1.7-33.4)$ & & \\
\hline $30-44$ & 9.1 & $(2.1-40.2)$ & & \\
\hline $18-29$ & 9.8 & $(2.3-42.7)$ & & \\
\hline \multicolumn{5}{|l|}{ Social support } \\
\hline High & 1.0 & & 1.0 & \\
\hline Medium & 0.8 & $(0.4-1.6)$ & 1.3 & $(0.8-2.2)$ \\
\hline Low & 2.1 & $(1.1-4.2)$ & 1.8 & $(1.0-3.2)$ \\
\hline \multicolumn{5}{|c|}{$\begin{array}{l}\text { Number of life } \\
\text { stressors } 12 \text { months } \\
\text { before March 11,2004 }\end{array}$} \\
\hline 0 & 1.0 & & 1.0 & \\
\hline $1-2$ & 2.4 & $(1.1-5.2)$ & 1.9 & $(1.1-3.1)$ \\
\hline 3 or more & 7.4 & $(3.3-16.4)$ & 7.1 & $(4.0-12.8)$ \\
\hline \multicolumn{5}{|c|}{$\begin{array}{l}\text { Symptoms of panic } \\
\text { attack during or soon } \\
\text { after the events }\end{array}$} \\
\hline No & 1.0 & & 1.0 & \\
\hline Yes & 8.2 & $(4.9-13.9)$ & 3.4 & $(2.1-5.4)$ \\
\hline \multicolumn{5}{|c|}{$\begin{array}{l}\text { Directly witnessed } \\
\text { the events }\end{array}$} \\
\hline No & 1.0 & & 1.0 & \\
\hline Yes, in person & 2.9 & $(1.5-5.7)$ & 1.7 & $(1.0-3.0)$ \\
\hline \multicolumn{5}{|l|}{$\begin{array}{l}\text { Fear of personal } \\
\text { injury or death }\end{array}$} \\
\hline No & & & 1.0 & \\
\hline Yes & & & 2.1 & $(1.4-3.2)$ \\
\hline
\end{tabular}

Note. PSTD $=$ posttraumatic stress disorder.

Fundamental differences between the two attacks likely explain these contrasts and provide insight into the cause of PTSD in the general population after mass traumas. Although both attacks were the largest attacks of their kind in both countries, the September 11 attacks resulted in approximately 2,800 fatalities, compared to the 191 fatalities in Madrid. Perhaps as importantly, the September 11 attacks on the WTC were a highly visible terrorist attack; approximately $20 \%$ of residents of New York City reported seeing the attacks in person compared to only $6.7 \%$ in this study (Galea et al., 2002). Similarly, life in New York City ground to a halt on the day of September 11, 2001, ensuring that all residents of the city were aware of the attacks and their potential consequences. However, the train bombings in Madrid were more circumscribed, and those persons who did not use the trains on a regular basis could go on with their day undisturbed.

This observation, then, argues for the presence of indirect exposure in the aftermath of mass trauma that is associated with the magnitude of the mass trauma and the 
extent to which persons in the general population are potentially exposed, albeit indirectly (e.g., through word of mouth, service disruptions, media, fear of subsequent attacks) to the mass traumatic event. Although previous work has suggested that television exposure may contribute to this indirect exposure to a terrorist attack (Ahern et al., 2002), we did not find television watching to be associated with PTSD in this sample. However, again in contrast to the September 11 attacks on the WTC, the March 11 bombings in Madrid made for far less graphic television images (i.e., images of already destroyed trains and persons being rescued compared to live images of airplanes hitting the WTC, people jumping from the towers, and the subsequent collapse of both towers).

There were several important similarities between the findings documented here and those documented after the September 11 attacks. First, the prevalence of current PTSD produced by other causes as well as the prevalence of lifetime PTSD (excepting current terrorism-related PTSD) was comparable in both studies, suggesting few systemic differences between the Madrid and New York City populations. Given the pervasiveness of global trade and cultural norms, the fact that these two populations are quite similar is not surprising and one might then expect that any number of Western cities would be comparable to the cities discussed here.

In addition, strikingly, the prevalences of current and lifetime depression were comparable in the Madrid and Manhattan samples. This study, much as the previous study in Manhattan did, suggests a twofold increase in current depression in the early aftermath of significant terrorist attacks over what might have been expected at baseline in the absence of these attacks (Demytternaere et al., 2004; ESEMeD/MHEDEA, 2004; Kessler et al., 1994). The observation that the prevalences of depression in Madrid and in Manhattan after the respective terrorist attacks were comparable, in contrast to the differences in current PTSD prevalences discussed previously, suggests that the cause of depression after such terrorist incidents is substantially different from the cause of PTSD. Although depression after disasters is far less commonly studied than is PTSD, mass bereavement may underlie depression after mass traumatic experiences. Given the dramatic nature of the March 11 bombings and the subsequent political turmoil linked directly to the bombings it is plausible that the bereavement that followed the Madrid bombings was not much different from that which followed the September 11 attacks in contrast to the likely substantial difference in actual direct exposure to the attacks between both incidents.

Multivariable analyses confirm the importance of factors that have previously been shown to be associated with mental health problems after traumatic event experiences. This study confirms the importance of social support, showing that low social support was associated with PTSD and almost reached the level of significance for depression (Norris $\&$ Kaniasty, 1996). The role of recent life stressors suggests that persons who experience them are particularly vulnerable to the consequences of terrorism. This group may be particularly important because they are probably readily identifiable in a clinical setting and may benefit from early screening and offers of mental health intervention.

This work confirms earlier findings that perievent emotional reactions may be an important early indicator of subsequent psychopathology after the experience of a mass trauma. Although here we specifically studied symptoms consistent with perievent panic attacks, similar observations have been reported for the experience of peritraumatic dissociation and subsequent risk of development of PTSD (Freedman, Brandes, Peri, \& Shalev, 1999). This association of peritraumatic emotional reactions with subsequent psychopathology, consistently with previous work (Galea et al., 2002), has important implications for public health screenings that may identify persons at risk for PTSD or depression early after a terrorist attack. We suggest that this presents a unique opportunity for population-level intervention, possibly based on cognitive-behavior principles, which addresses perievent emotional reactions and minimizes subsequent PTSD and depression (Resnick, Acierno, Holmes, Kilpatrick, \& Jager, 1999). For example, early reports suggest that Internet-based cognitive-behavioral interventions that target, among other phenomena, peritraumatic stress reactions have the potential to minimize the longer-term mental health consequences of mass trauma (Ruggiero et al., in press). 
There are several considerations important for interpretation of this study. We used telephone interviews to identify cases of PTSD and depression. Although it has been shown that telephone assessment and in-person assessment of Axis I disorders, including anxiety disorders and affective disorders, produce comparable estimates of symptoms (Paulsen, Crowe, Noyes, \& Pfohl, 1988), PTSD and depression assessed in this manner cannot be equated to a full diagnosis, and comparisons between the results of this study and other work that uses clinical assessments of psychopathology should be made prudently. Also, the observations drawn here may be biased by survey nonrespondents. The comparability of our sample to expected population demographics and the fact that the response rates obtained in this study are comparable to those in similar work both are reassuring in this regard (Galea et al., 2004; Mariolis, 2001, 2002).

We note that although we collected data on a comprehensive set of potential determinants of psychopathology in the aftermath of a disaster we still did not collect data on some factors that may be important. For example we did not collect information on peritraumatic dissociation, a perievent emotional reaction that has been shown to be predictive of PTSD after traumatic event experiences (Freedman et al., 1999). This lack of data should be considered when drawing inferences about the covariates found to be significant determinants of PTSD or depression in this analysis as in any other analysis that considers determinants of disease within a multivariate framework.

In particular, the variables that were considered in this study are based on a conceptual understanding of the multivariate determinants of the consequences of mass trauma (Freedy, Kilpatrick, \& Resnick, 1993). Therefore, the focus on these given variables is not intended to preclude other variables that may be important determinants of mental health after terrorism and the recovery from mental illness after terrorism. For example, recovery from terrorism could be viewed from a coping perspective in which perceived levels of control are important and interact with both peritraumatic responses and other important contextual variables (e.g., life context and environmental resources) not measured here. Also, perceptions of coping efficacy can determine a sense of perceived control and may provide a mediating factor that predicts PTSD and/or depression (Benight \& Bandura, 2004). Future research would do well to consider the full scope of covariates that may determine the consequences of terrorism and the pathways that explicate the relation between these determinants and mental health.

In conclusion, we document differences and similarities between psychopathology in Madrid after the March 11, 2004, train bombings and in Manhattan after the September 11, 2001, terrorist attacks. Taken in concert, these findings suggest that the magnitude of a terrorist attack may be the primary determinant of the prevalence of PTSD in the general population but that other factors may be responsible for determining the population prevalence of depression. Also, a recent history of stressors and peritraumatic emotional reactions may identify persons who are vulnerable to the psychological consequences of terrorism. Persons who have experienced recent stressors may be identified by clinicians, whereas peritraumatic emotional reactions may be the basis of population-level interventions in the aftermath of terrorist attacks.

\section{REFERENCES}

Ahern, J., Galea, S., Resnick, H., Kilpatrick, D., Bucuvalas, M., Gold, J., et al. (2002). Television images and psychological symptoms after the September 11 terrorist attacks. Psychiatry, 65, 289-300.

American Association for Public Opinion Research Standard Definitions: Final dispositions of case codes and outcome rates for surveys. The American Association for Public Opinion Research, 2003. Retrieved January 16, 2004, from http://www.aapor.org/pdfs/newstandarddefinitions.pdf

Benight, C. C., \& Bandura, A. (2004). Social cognitive theory of posttraumatic recovery: The role of perceived self-efficacy. Behaviour Research \& Therapy, 42, 1129-1148.

Blanchard, E. B., Jones-Alexander, J., Buckley, T. C., \& Forneris, C. A. (1996). Psychometric properties of the PTSD checklist. Behavior Research and Therapy, 34, 669-673.

Bleich, A., Gelkopf, M., \& Solomon, Z. (2003). Exposure to terrorism, stress-related mental health symptoms, and coping behaviors among a nationally representative sample in Israel. Journal of the American Medical Association, 290, 612-620. 
Boscarino, J. A., Galea, S., Adams, R. E., Ahern, J., Resnick, H., \& Vlahov, D. (2004). Mental health service and medication use in New York City after the September 11, 2001, terrorist attack. Psychiatric Services, 55, 274-283.

Boscarino, J. A., Galea, S., Ahern, J., Resnick, H., \& Vlahov, D. (2003). Psychiatric medication use among Manhattan residents following the World Trade Center disaster. Journal of Traumatic Stress, 16, 301-306.

Demyttenaere, K., Bruffaerts, R., Posada-Villa, J., Gasquet, I., Kovess, V., Lepine, J. P., et al. (2004). Prevalence, severity, and unmet need for treatment of mental disorders in the World Health Organization World Mental Health Surveys. Journal of the American Medical Association, 291, 2581-2591.

Derogatis, L. R. (2001). Brief Symptom Inventory 18 (BSI-18). Manual. Minnetonka, MN: NCS Assessments.

ESEMeD/MHEDEA 2000 Investigators. (2004). Prevalence of mental disorders in Europe: Results from the European Study of the Epidemiology of Mental Disorders (ESEMeD) project. Acta Psychiatrica Scandinavica, 109 (Suppl. 420), 21-27.

Foa, E. B., Davidson, J. R., \& Frances, A. (Eds.). (1999). The expert consensus guideline series: Treatment of Posttraumatic Stress Disorder. Journal of Clinical Psychiatry, 60 (Suppl. 16), 4-32.

Freedman, S. A., Brandes, D., Peri, T., \& Shalev, A. (1999). Predictors of chronic post-traumatic stress disorder: A prospective study. British Journal of Psychiatry, 174, 353-359.

Freedy, J. R., Kilpatrick, D. G., \& Resnick, H. S. (1993). Natural disasters and mental health: Theory, assessment, and intervention. Journal of Social Behavior and Personality, 8(5), 49-103.

Galea, S., Ahern, J., Resnick, H., Kilpatricl, D., Bucuvalas, M., Gold, J., et al. (2002). Psychological sequelae of the September 11 terrorist attacks in New York City. New England Journal of Medicine, 346, 982-987.

Galea, S., Boscarino, J., Resnick, H., \& Vlahov, D. (2003) Mental health in New York City after the September 11 terrorist attacks: Results from two population surveys. In R. W. Manderscheid \& M. J. Henderson (Eds.), Mental health, United States, 2001 (pp. 83-91). Washington, DC: Superintendent of Documents, United States Government Printing Office.

Galea, S., Vlahov, D., Resnick, H., Ahern, J., Susser, E., Gold, J., et al. (2003). Trends of probable post-traumatic stress disorder in New York City after the September 11th terrorist attacks. American Journal of Epidemiology, 158, 514-524.

Galea, S., Vlahov, D., Tracy, M., Hoover, D., Resnick, H., \& Kilpatrick, D. G. (2004). Hispanic ethnicity and post-traumatic stress disorder after a disaster: Evidence from a general popula- tions survey after September 11. Annals of Epidemiology, 14, 520-531.

Hanson, R. F., Kilpatrick, D. G., Freedy, R., \& Saunders, B. E. (1995). Los Angeles County after the 1992 civil disturbances: Degree of exposure and impact on mental health. Journal of Consulting and Clinical Psychology, 63, 987-996.

Instituto Nacional de Estadística. (2004). Equipamiento de teléfono de las viviendas principales espańolas por Valor absoluto/porcentaje, Comunidad Autónoma y tipo de teléfono. Retrieved January 29, 2004, from http://www.ine.es.

Kessler, R. C., McGonagle, K. A., Zhao, S., Nelson, C. B., Hughes, M., Eshleman, S., et al. (1994). Lifetime and 12-month prevalence of DSM-III-R psychiatric disorders in the United States: Results from the National Comorbidity Survey. Archives of General Psychiatry, 51, 8-19.

Kilpatrick, D. G., Acierno, R., Resnick, H. S., Saunders, B. E., \& Best, C. L. (1997). A 2 year longitudinal analysis of the relationships between violent assault and substance use in women. Journal of Consulting and Clinical Psychology, 65, 834-847.

Kilpatrick, D. G., Resnick, H. S., Freedy, J. R. Pelcovitz, D., Resick, P. A., Roth, S., et al. (1998). The Posttraumatic Stress Disorder field trial: Evaluation of the PTSD construct-Criteria A through E. In T. A. Widiger, A. J. Frances, H. A. Pincus, M. B. First, R. Ross, \& W. Davis (Eds.), DSM-IV sourcebook (Vol. 4, pp. 803844). Washington, DC: American Psychiatric Association Press.

Kilpatrick, D. G., Ruggiero, K. J., Acierno, R., Saunders, B. E., Resnick, H. S., \& Best, C. L. (2000). Violence and risk of PTSD, major depression, substance abuse/dependence and comorbidity: Results from the National Survey of Adolescents. Journal of Consulting and Clinical Psychology, 71, 692-700.

Mariolis, P. (2001). Data accuracy: How good are our usual indicators? Proceedings of Statistics Canada Symposium 2001: Achieving Data Quality in a Statistical Agency: A Methodologic Perspective. Retrieved January 6, 2005, from http://www.statcan.ca/english/freepub/11-522$\mathrm{XIE} / 2001001 /$ session2/s2b.pdf

Mariolis, P. (2002 May),. Response rates and data accuracy. Presentation at the American Association of Public Opinion Research, Nashville, TN.

Miguel-Tobal, J. J., González Ordi, H., \& López Ortega, E. (2000). Estrés postraumático: Hacia una integración de aspectos psicológicos y neurobiológicos. Ansiedad y Estrés, 6, 255-280.

Norris, F. H., \& Kaniasty, K. (1996). Received and perceived social support in times of stress: A test of the social support deterioration deterrence model. Journal of Personality and Social Psychology, 71, 498-511. 
Norris, F. H., Friedman, M.J., Watson, P. J., Byrne, C. M., Diaz, E., \& Kaniasty, K. (2002a). 60,000 disaster victims speak: Part 1. An empirical review of the empirical literature, 1981-2001. Psychiatry, 65, 207-239.

Norris, F. H., Friedman, M. J., \& Watson, P. J. (2002b). 60,000 disaster victims speak: Part 2. Summary and implications of the disaster mental health research. Psychiatry, 65, 240260 .

North, C. S., Nixon, S. J., Shariat, S., Mallonee, S., McMillen, J. C., Spitznagel, E. L., et al. (1999). Psychiatric disorders among survivors of the Oklahoma City bombing. Journal of the American Medical Association, 282, 755-762.

Paulsen, A. S., Crowe, R. R., Noyes, R., \& Pfohl, B. (1988). Reliability of the telephone interview in diagnosing anxiety disorders. Archives of General Psychiatry, 45, 62-63.

Resnick, H., Acierno, R., Holmes, M., Kilpatrick, D. G., \& Jager, N. (1999). Prevention of post-rape psychopathology: Preliminary findings of a controlled acute rape treatment study. Journal of Anxiety Disorders, 13, 359-370.

Resnick, H. S., Kilpatrick, D. G., Dansky, B. S., Saunders, B. E., \& Best, C. (1993). Prevalence of civilian trauma and posttraumatic stress disorder in a representative national survey of women. Journal of Consulting and Clinical Psychology, 61, 984991.

Ruggiero, K. J, Resnick, H.S., Acierno, R., Coffey, S. F., Carpenter, M. J., et al. (in press). Internet-based intervention for mental health and substance use problems in the aftermath of mass violence and disasters: A pilot feasibility study. Behavior Therapy.

Schlenger, W., Cadell, J., Ebert, L., Jordan, B. K., Rourke, K. M., Wilson, D., et al. (2002). Psychological reactions to terrorist attacks: Findings from the National Study of Americans' Reactions to September 11. Journal of the American Medical Association, 288, 581-588.

Shalev, A. Y., Tuval-Mashiach, R., \& Hadar, H. (2004). Posttraumatic stress disorder as a result of mass trauma. Journal of Clinical Psychiatry, 65(Suppl. 1), 4-10.

Silver, R. C., Holman, E. A., McIntosh, D. N., Poulin, M., \& Gil-Rivas, V. (2002). Nationwide longitudinal study of psychological responses to September 11. Journal of the American Medical Association, 288, 1235-1244.

Spitzer, R. L., Williams, J. B. W., Gibbon, M., \& First, M. B. (1992). The Structural Clinical Interview for DSM-III-R (SCID): 1 . History, rationale, and description. Archives of General Psychiatry, 49, 624-629. 